\title{
Detection of seven Candida species using the Light-Cycler system
}

\author{
P. Lewis White, Anjali Shetty and Rosemary A. Barnes \\ Department of Medical Microbiology and PHLS, University Hospital Wales, Heath Park, Cardiff CF14 \\ $4 \mathrm{XN}, \mathrm{UK}$
}

Correspondence
P. Lewis White
lewis.white@phls.wales.nhs.uk

Received 16 August 2002

Accepted 12 November 2002

\begin{abstract}
Due to the limitations of classical methods for the detection of systemic fungal infections and the high mortality rates associated with these infections, it has become essential to develop a quick, sensitive and specific detection assay. By using the Idaho Technologies Light-Cycler system, a qualitative real-time PCR system has been developed for the detection of the leading causes of systemic infection within the genus Candida. The sensitivity of the assay was comparable to previously described PCR methods $\left(1-5\right.$ c.f.u. $\mathrm{ml}^{-1}$ ) and, by the use of a single Candida probe, it was able to detect, but not differentiate between, seven species of Candida (Candida albicans, Candida dubliniensis, Candida glabrata, Candida kefyr, Candida krusei, Candida parapsilosis and Candida tropicalis). Single-round amplification on the Light-Cycler allowed rapid turn-around of clinical samples (within one working day) and it was shown to be more sensitive than classical procedures, exposing 39 possible systemic infections that were not detected by blood culture.
\end{abstract}

\section{INTRODUCTION}

It has been widely published and accepted that invasive fungal infections are a major cause of morbidity and mortality in the immunocompromised patient (Whimbey et al., 1987; Denning, 1998; Wright \& Wenzel, 1997), and Candida species have become the fourth most-frequent cause of nosocomial blood-stream infection in critically ill patients (Nishikawa et al., 1999). With further advances in medical intervention and the increasing population of immunocompromised patients, the list of human fungal pathogens continues to grow (Chen et al., 2000); within the genus Candida, there has been an increase in the incidence of infection with species other than Candida albicans (Reiss \& Morrison, 1993; Gleason et al., 1997).

Early initiation of antifungal therapy is paramount in reducing the high mortality rates associated with fungaemia (Morace et al., 1997) and is dependent on early detection of the fungal infection. The current 'gold standard' for detection of systemic infection is blood culture, but this is believed to lack sensitivity and has been shown to be positive in less than $50 \%$ of patients with chronic disseminated candidiasis and is rarely positive for patients with invasive aspergillosis (Einsele et al., 1997). Culture techniques are also timeconsuming, taking up to 3 weeks, an unacceptable period for the treatment of fungaemia. Conversely, the lack of a reliable early diagnostic marker may lead to the unnecessary empiri-

Abbreviations: FRET, fluorescence resonance energy transfer; NASBA, nucleic acid sequence-based amplification; RFLP, restriction fragment length polymorphism. cal treatment of patients who do not have fungal infections. The end result is unacceptable toxicity in many patients and massive expense; it is estimated that the UK National Health

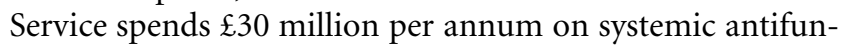
gals, and this is set to rise.

It is essential to overcome the limitations of the traditional culture-based fungal detection methods and replace them with rapid and sensitive procedures that are capable of detecting non-culturable/non-viable cells or circulating free fungal DNA (i.e. molecular methods). Recently, many groups have developed molecular-based assays for the detection of fungal DNA. Examples of this include more traditional molecular techniques such as comparison of DNA sequence and polymorphism (Chen et al., 2000), restriction fragment length polymorphisms (RFLP) (Morace orace et al., 1997), Southern blotting (Einsele et al., 1997), nested PCR (Jaeger et al., 2000; Mathis et al., 1997) and typing methods such as random amplification of polymorphic DNA (RAPD) (Metzgar et al., 1998; Lehmann et al., 1992). The major drawback with these techniques is that they require post-amplification handling and, as such, increase the time to result and, more importantly, the chance of contamination. These limitations have led to the development of 'real-time' molecular assays that dispense with the need for post-amplification handling and are therefore leading the diagnostic molecular field forward.

Detection of candidal and Aspergillus RNA from clinical samples has been developed using nucleic acid sequencebased amplification (NASBA) (Widjojoatmodjo et al., 1999; Loeffler et al., 2001). NASBA is an isothermal nucleic acid 
amplification process using avian myeloblastosis virus reverse transcriptase (AMV-RT), RNase $\mathrm{H}$ and T7 RNA polymerase. Detection is determined by enhanced chemiluminescence (ECL, 'end-point' detection) or by molecular beacon ('real-time' detection). Both the amplification and 'end-point' detection procedures have been described previously (Widjojoatmodjo et al., 1999; Loeffler et al., 2001) and so will not be included here. Like all molecular assays, NASBA has high sensitivity and specificity, but, unlike DNAbased assays, it requires less starting material and has a quicker nucleic acid extraction procedure. A drawback with NASBA is that the amplification/end-point detection process takes considerably longer than when using a Light-Cycler and the difference in the overall time to result is therefore negligible. Furthermore, NASBA RNA targets are less stable than their DNA counterparts and this, coupled with the ubiquitous nature of RNases, may be problematic in a diagnostic setting.

Detection of fungal DNA from clinical Candida species has been developed on the TaqMan PCR system, but this has only been used for rapid identification of cultured Candida species and, as yet, nothing has been published describing the detection of non-culturable/non-viable cells (Guiver et al., 2001).

Alternative DNA-detection methods have been developed utilizing the Roche Diagnostics Light-Cycler (Loeffler et al., 2000a, b), but these are not suitable for use on the Idaho Technologies Light-Cycler system. Loeffler et al. (2000b) described their procedure for the detection of C. albicans and Aspergillus fumigatus using the Roche Diagnostics LightCycler. Despite the principles of both the Roche and the Idaho Light-Cycler systems being the same (use of small volume, rapid thermocycling and real-time, in-tube fluorescence detection of the PCR product), it was not possible to transfer the procedure of Loeffler et al. (2000b) on to the Idaho Light-Cycler. The problems appeared to be due to the production of primer dimers and primer-probe dimers which, in turn, led to the production of dimer melting curves that interfered when determining results. In addition, the probe designed by Loeffler et al. (2000b) was specific for $C$. albicans, but with the increasing incidence of infection with non-C. albicans Candida species, it was decided that it would be beneficial to have a probe that could detect the major infectious Candida species.

The Candida probe is based on a system different from that of Loeffler et al. (2000b), who developed a hybridization probe. In their assay, a fluorescence resonance energy transfer (FRET) system relies on two fluorescently labelled probes, a donor and an acceptor, which bind in a head-to-tail orientation. When together, there is an energy transfer between the fluorescent dyes, leading to an emission of red fluorescent light from the acceptor probe, which is measured by the photohybrids in the Light-Cycler. Our system uses a single biprobe that is labelled with the fluorescent dye Cy5; the fluorescent dye SYBR green is used to detect the PCR amplicon. The probe will only emit fluorescence when bound to the PCR amplicon; when bound, it accepts energy from the fluorescent dye SYBR green, which binds to the minor groove on double-stranded DNA. The advantage of this system is the simplicity of a single probe, although a setback is the generation of a SYBR green signal due to non-specific amplification or the production of primer-probe dimers. Following each amplification cycle, the fluorescence of both the probe and amplicon is monitored and, provided the target DNA template is present, the fluorescence increases with every cycle. The cycle at which the fluorescence rises above background is known as the crossing-point. This represents the start of detectable amplification/probe binding and is dependent on the initial template concentration.

After the amplification process, the amplicons are gradually exposed to an increasing temperature and the fluorescence of both the probe and amplicon is monitored continually during this process. As the temperature passes through the denaturation point (the melting temperature) of firstly the probe and then the amplicon, a dramatic fall in fluorescence is observed and a melting curve is generated. The data are then converted into melting peaks by the Light-Cycler software, which filters out background fluorescence and plots the negative derivative of fluorescence with respect to temperature ( $-\mathrm{dF} / \mathrm{dT}$ vs $\mathrm{T})$.

We report a 'real-time' PCR assay for the detection of clinically relevant Candida. Unlike previous publications, the assay was suitable for use on the Idaho Technologies Light-Cycler and was able to detect the seven main pathogenic species of Candida. The assay was as sensitive as previously described methods and this could be improved by the use of a nested system.

\section{METHODS}

Fungal cultures. Ten strains of $C$. albicans, one strain of Candida dubliniensis, one strain of Candida famata, 10 strains of Candida glabrata, four strains of Candida guillermondii, five strains of Candida kefyr, five strains of Candida krusei, one strain of Candida lipolytica, eight strains of Candida parapsilosis, six strains of Candida tropicalis, 10 strains of Aspergillus fumigatus, five strains of Aspergillus niger, one strain of Cryptococcus neoformans and two strains of Saccharomyces cerevisiae were obtained from our clinical culture collection and grown on Sabauraud's glucose agar for $3-4$ days at $30^{\circ} \mathrm{C}$. Yeast species were originally identified by colorimetric sugar-utilization tests (Auxacolour; Bio-Rad), chlamydaspore production and microscopy, while the moulds were identified by microscopy. To confirm their identity, DNA was extracted from the species and part of the 18S rRNA gene (a region spanning positions 550-760 in the $18 \mathrm{~S}$ rRNA gene of $C$. albicans, accession no. M60302.1) was amplified by PCR and sequenced. All identities were confirmed. The night before extractions were to be carried out, glucose broth was inoculated with the fungi and incubated overnight at $30^{\circ} \mathrm{C}$. If whole EDTA-blood specimens were spiked with fungi, serial dilutions were carried out using sterile saline solutions until the desired fungal load was achieved. This was checked by plate counts and by using Fuchs-Rosenthal counting chambers.

Controls. Blood from healthy individuals and water were included as negative extraction controls. In addition to the negative controls, when extractions were carried out from clinical samples, blood from a healthy individual was spiked with the desired fungal load $\left(<10\right.$ c.f.u. $\left.\mathrm{ml}^{-1}\right)$ 
and the sample was included as a positive extraction control. For each Light-Cycler experiment, the extraction controls plus a positive PCR control (DNA from a cultured Candida strain) and two negative PCR controls (DNA from a cultured Aspergillus strain and water) were included.

Clinical samples. Clinical samples were requested from patients thought to be at risk from fungal infection (pyrexia, neutropenia and no response to antibacterial antibiotics). In an on-going pilot study, 472 whole EDTA-blood samples from 113 patients were tested by both the single-round Light-Cycler assay and by the nested PCR method. Of these patients, 35 were receiving treatment for leukaemia, 27 were bonemarrow-transplant patients, 19 were suffering various types of lymphoma, six were receiving treatment for myeloma and four were suffering from pneumonia. The remaining 22 patients had a variety of disorders including premature birth, aplastic anaemia, oesophageal rupture, AIDS, respiratory failure and liver cirrhosis, but all were pyrexic and not responding to antibacterial antibiotics and were considered at high risk for fungal infection.

Twice weekly, $5 \mathrm{ml}$ EDTA-whole blood from each patient was sent to the laboratory, where it was transferred to a sterile universal tube and frozen $\left(-80^{\circ} \mathrm{C}\right)$ until the day of the DNA extraction. At the request of the clinician or if the specimen was positive, further samples were sent and analysed. Only patients with more than one sample have been included in this study.

In addition to the blood samples sent for fungal PCR and blood culture, a variety of superficial samples were sent for culture. These included a range of swabs (mouth, throat, skin, genital and wound swabs), sputum, urine and faecal samples.

DNA extraction. DNA was extracted as described by Loeffler et al. (1997) using recombinant lyticase (Sigma-Aldrich) and the Qiamp tissue kit (Qiagen) with two minor modifications. Firstly, when precipitating DNA with ethanol, the solution was incubated on ice for $30 \mathrm{~min}$; this was found to increase the yield of DNA. Secondly, after the elution of the DNA, YM-100 microconcentrators (Millipore) were used to increase the DNA concentration. All reagents were filter-sterilized through $0 \cdot 2 \mu \mathrm{m}$ filters before use.

Primer and probe design. When designing the pan-fungal primers, over 100 18S rRNA sequences from pathogenic fungi were downloaded from the NCBI database. These included 10 different genera and 40 different species and, when the primers were entered into a BLAST search (Altschul et al., 1997), the top 500 matches were all fungal. In designing the Candida probe, 50 sequences from the seven most prevalent species of Candida were compared using DNASIS 2.5 (Hitachi Software Engineering Co.).

\section{PCR}

Light-Cycler assay. The Light-Cycler used was designed and manufactured by Idaho Technologies (Bio/gene) and all primers and probes were purchased from Oswel Research Products. The primers (L18F, 5'CTCGTAGTTGAACCTTGG; L18R, 5'-GCCTGCTTTGAACACTCT) were pan-fungal and were designed to bind to two conserved regions encompassing a variable region within the $18 \mathrm{~S}$ rRNA gene. PCR amplification produced a $140 \mathrm{bp}$ amplicon that corresponded to the region spanning positions $620-760$ in the $18 \mathrm{~S}$ rRNA gene of C. albicans.

The amplified product was detected by the presence of a SYBR green fluorescent signal and a Cy5-labelled probe (Candida probe, 5'TTTTGATGCGTACTGGACCCTGT) was used to bind to a Candidaspecific sequence within the PCR amplicon.

The PCR mixture consisted of $5 \mu \mathrm{l}$ Light-Cycler master-mix (Biogene), which contained the dNTPs, exo-Taq DNA polymerase, $3 \mathrm{mM}$ magnesium chloride, TaqStart antibody (Sigma), 0.5 $\mu \mathrm{l}$ of each primer (final concentration $600 \mathrm{nM}$ ), $0 \cdot 5 \mu \mathrm{l}$ SYBR green (diluted 1:1000, as recommended by Biogene), $1 \mu \mathrm{l}$ Candida probe (final concentration $300 \mathrm{nM}$ ) and $1 \mu \mathrm{l}$ template DNA and the mixture was made up to $10 \mu \mathrm{l}$ with molecular-grade water.

The PCR program was one cycle of denaturation at $95^{\circ} \mathrm{C}$ for $15 \mathrm{~s}$ followed by 60 cycles of $95{ }^{\circ} \mathrm{C}$ for $0 \mathrm{~s}$, annealing at $62^{\circ} \mathrm{C}$ for $2 \mathrm{~s}$ and extension at $74{ }^{\circ} \mathrm{C}$ for $2 \mathrm{~s}$. The Light-Cycler was then programmed to carry out a melting cycle to determine the melting temperature of the amplicon and probe. This consisted of a denaturing step at $95^{\circ} \mathrm{C}$ for 15 $\mathrm{s}$, after which the Light-Cycler cooled to $50{ }^{\circ} \mathrm{C}$ and then increased the temperature at a rate of $0 \cdot 2{ }^{\circ} \mathrm{C} \mathrm{s}^{-1}$ until the temperature reached $95{ }^{\circ} \mathrm{C}$. During this stage, the Light-Cycler was continuously measuring the fluorescence.

Nested PCR assay. To improve the sensitivity of the assay, a nested PCR was developed combining both a block-based PCR machine (Crocodile III, Appligene) and the Light-Cycler system. The first round (block-based) PCR used pan-fungal primers (182F, 5'-GAGGG CAAGTCTGGTG; 18R2, 5'-CCTGCTTTGAACACTCTAA) targeting the $18 \mathrm{~S}$ rRNA gene and spanned the PCR amplicon described above. Amplification by PCR produced a $210 \mathrm{bp}$ amplicon that corresponded to the region spanning positions $550-760$ in the 18S rRNA gene of $C$. albicans.

The PCR mixture consisted of $5 \mu 110 \times$ PCR buffer, $5 \mu$ dNTPs (final concentration $200 \mathrm{nM}$ ), $2 \mu$ l of each primer (final concentration 500 $\mathrm{nM}), 0.5 \mu \mathrm{l}(2.5 \mathrm{U})$ of Taq DNA polymerase (Sigma) and $5 \mu \mathrm{l}$ DNA template, made up to $50 \mu \mathrm{l}$ with molecular-grade water. The PCR program consisted of one cycle of denaturation at $94{ }^{\circ} \mathrm{C}$ for $5 \mathrm{~min}$ followed by 35 cycles of $94{ }^{\circ} \mathrm{C}$ for $1 \mathrm{~min}, 59^{\circ} \mathrm{C}$ for $1 \mathrm{~min}$ and $72{ }^{\circ} \mathrm{C}$ for $1.5 \mathrm{~min}$ and, finally, one cycle at $72{ }^{\circ} \mathrm{C}$ for $7 \mathrm{~min}$. Aliquots of $5 \mu \mathrm{l}$ of the PCR amplicons were then electrophoresed on a TAE $/ 2 \%$ agarose gel and visualized under UV light after staining with ethidium bromide. Of the remaining $45 \mu \mathrm{l}$ of amplicon, $10 \mu \mathrm{l}$ was diluted $(1: 50)$ before the second-round PCR was carried out on the Light-Cycler as described above.

Contamination control. Before any stage of the experiment [DNA extraction, PCR master-mix preparation (first and second round), addition of template to master-mix (first and second round), PCR amplification (first and second round)] was performed, all worksurfaces including cabinets, pipettes, racks and microcentrifuges, including rotors and adaptors, were wiped down with Microsol (Anachem) and DNAzap (Ambion).

Each stage, including the first and second rounds of amplification, was carried out in separate laboratories that were independently equipped, including laboratory coats. To prevent DNA carry-over, personnel performing the DNA extraction were not allowed to carry out the PCR set-up on the same day.

All PCR reagents were aliquotted into single-use sterile tubes in a UVtreated clean cupboard that was also used for PCR master-mix set-up. The aliquotted master-mix was transferred to another room for addition of the template. After addition of the DNA, the PCR mixture was transferred to the correct amplification room, dependent on whether it was a single-round PCR assay or the first round of the nested-PCR assay.

After the first round of the nested PCR, the products were diluted using diethyl pyrocarbonate-treated water (Ambion) that had been dispensed in a clean cabinet. The diluted products were transferred to the second amplification room, where they were added to the second PCR mastermix (prepared in a clean cabinet) in another cabinet to prevent contamination with previously aerosolized amplicons.

Before any transfer racks were returned to their original rooms, they were soaked in Microsol and wiped down with DNAzap. 
RFLP detection of Aspergillus. In addition to the Candida PCR, each sample was tested by RFLP for the presence of Aspergillus DNA. After the second round of the nested PCR, each amplicon was purified using Qiaquick columns (Qiagen) and then, to determine the amplicon concentration, the product was analysed by $1 \%$ agarose gel electrophoresis. RFLP digestion was performed by using up to $17 \mu \mathrm{l}$ of the purified amplicon mixed with $1 \mu \mathrm{l}(10 \mathrm{U})$ of the restriction enzyme ScaI (Amersham Pharmacia Biotech) and $2 \mu \mathrm{l}$ of the buffer supplied. This was incubated for $3 \mathrm{~h}$ at $37^{\circ} \mathrm{C}$. The digested product was then analysed by $4 \%$ Metaphor agarose (Flowgen) gel electrophoresis. The undigested amplicons were 140-160 bp in size, depending on the species and genus of the fungus. After the digestion, DNA from Aspergillus species was cut into two fragments, of 100 and 50-60 bp. All fragment sizes were determined against a molecular mass marker (PCR marker 50-2000 bp; Sigma) (see Fig. 1).

\section{RESULTS}

\section{PCR amplification}

Using the pan-fungal primers, the 14 species (four genera) tested all provided the expected size of PCR amplicon (140 bp for yeast, 150-160 bp for moulds). Sequencing revealed the amplicons to be the expected targets (results not shown).

\section{Detection of Aspergillus by RFLP}

A ScaI digest differentiated the seven Aspergillus species (A. fumigatus, Aspergillus flavus, A. niger, Aspergillus nidulans, Aspergillus candidus, Aspergillus terreus and Aspergillus oryzae) from the 12 yeast species tested (C. albicans, $C$. dubliniensis, C. glabrata, C. guillermondii, C. kefyr, C. krusei, C. lipolytica, C. parapsilosis, C. tropicalis, Cryptococcus neoformans and S. cerevisiae) (Fig. 1). Digestion with ScaI cut the Aspergillus amplicon (150-160 bp) into two fragments, of 100 and $50 \mathrm{bp}$, although some undigested amplicon was apparent. None of the yeast amplicons possessed the correct recognition sequence for ScaI and so the PCR amplicon remained undigested (Fig. 1).

\section{Specificity of the Candida probe}

Using DNA extracted from the cultured fungi, the Candida probe was tested for its specificity. The Candida probe hybridized with C.albicans, C. kefyr, C. krusei, C. dubliniensis, C. tropicalis, C. parapsilosis and C. glabrata but would not hybridize to DNA from C. guillermondii, C. lipolytica, $C$. famata, A. fumigatus, A. niger, S. cerevisiae or Cryptococcus neoformans. All the species tested produced an amplicon, as represented by the SYBR green peak on the melting profiles, but only the afore-mentioned seven Candida species produced a Cy5 (probe) signal, giving rise to the representative double-peaked melting profile (Fig. 2). The melting temperature of the Candida probe was between 59 and $62^{\circ} \mathrm{C}$ and the PCR amplicon melted at between 87 and $89^{\circ} \mathrm{C}$; both melting temperatures were dependent on the species being used in the experiment.

When tested with DNA extracted from blood donated from healthy individuals, although some non-specific amplifica-

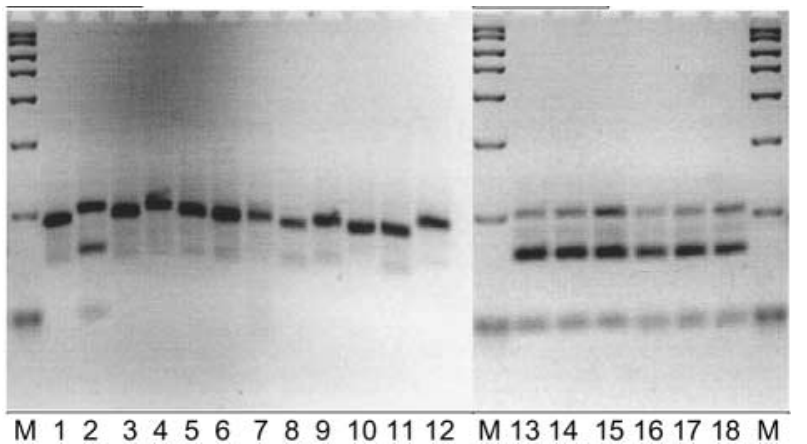

Fig. 1. TAE/4\% Metaphor agarose gels showing Scal digestion of L18F/L18R amplicons. Lanes: M, markers; 1, C. albicans; 2, A. oryzae; 3, C. dubliniensis; 4, C. glabrata; 5, C. guillermondii; 6, C. kefyr; 7, C. krusei; 8, C. lipolytica; 9, C. parapsilosis; 10, C. tropicalis; 11, Cryptococcus neoformans; 12, Saccharomyces cerevisiae; 13, A. fumigatus; 14, A. flavus; 15, A. niger; 16, A. nidulans; 17, A. candidus; 18, A. terreus. Molecular mass marker sizes: 2000, 1500, 1000, 750, 500, 300, 150 and $50 \mathrm{bp}$.

tion occurred, no probe hybridization was seen. This was also true for blood spiked with 0 c.f.u. C. albicans $\mathrm{ml}^{-1}$ (Fig. 3). It was noted in all tests that, even when no fungal cells/DNA were present, some non-specific amplification occurred. The absence of any probe signal confirmed that it was not one of the medically important Candida species tested for. Multiple attempts to sequence the amplified products resulted in incoherent data, indicating that amplification was nonspecific.

\section{Sensitivity of the single-round Candida PCR assay}

In order to find the lower limit of sensitivity, blood from healthy individuals spiked with $C$. albicans cells in the range $2.5 \times 10^{2}$ to 0 c.f.u. $\mathrm{ml}^{-1}$ was tested. Using this technique, we were able to detect Candida down to a reproducible limit of 5 c.f.u. $\mathrm{ml}^{-1}$ (Fig. 3), a sensitivity that corresponded to the reproducible detection limit using the Roche Light-Cycler/ FRET-based system (Loeffler $e$ t al., 2000b). It was found that, if the extraction modifications noted earlier in this publication were not applied, the reproducible detection limit increased to $20-30$ c.f.u. $\mathrm{ml}^{-1}$ whole blood.

\section{Reproducibility of the assay}

In total, spiked whole blood $\left(10^{3}\right.$ to 0 c.f.u. $\left.\mathrm{ml}^{-1}\right)$ from healthy individuals was extracted on five separate occasions and, for each extraction, the Candida PCR was repeated three times. Each time, the same results were achieved, with the lower sensitivity always being 5 c.f.u. $\mathrm{ml}^{-1}$. Since the development of the assay, 100 clinical experiments have been carried out and only twice have the positive extraction controls $\left(<10\right.$ c.f.u. $\left.\mathrm{ml}^{-1}\right)$ failed to work and, on both occasions, this could be attributed to errors during the extraction procedure. 


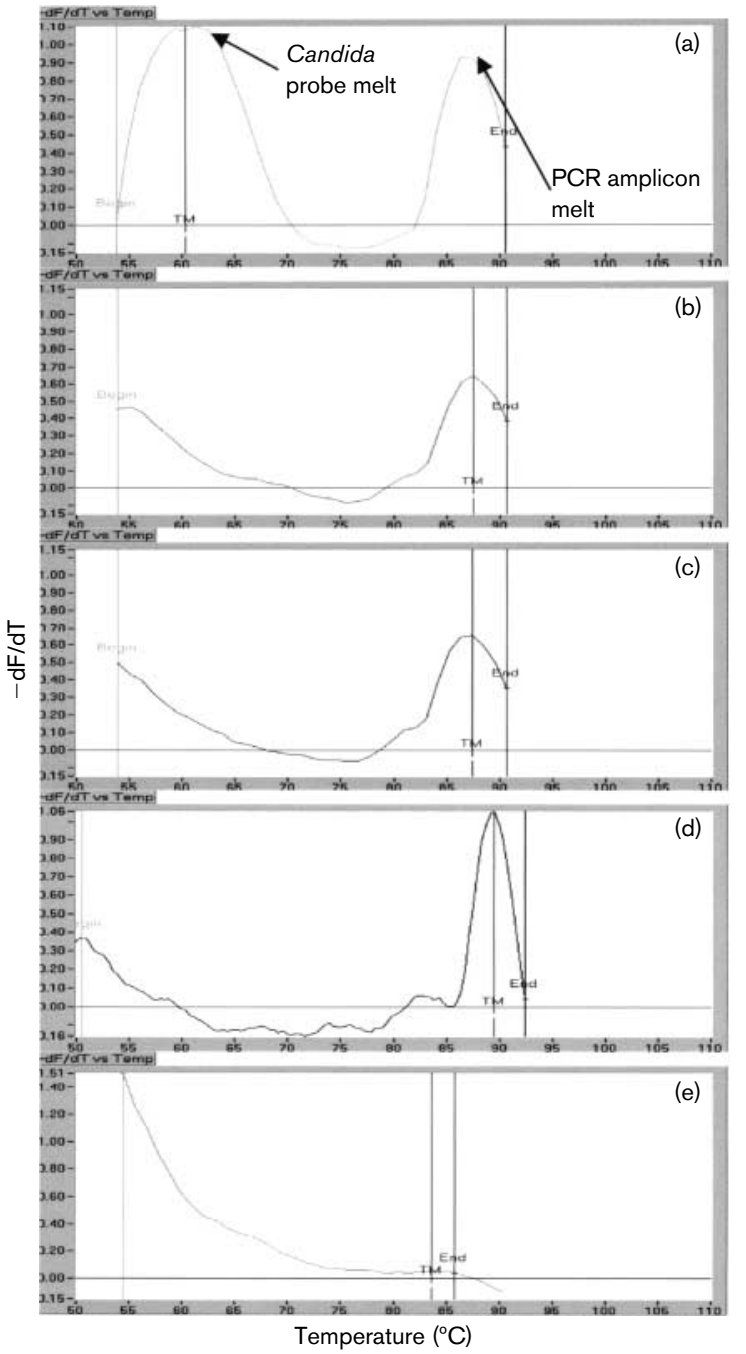

Fig. 2. Representative melting profiles of (a) a species detected by the Candida probe (C. albicans), (b) - (d) three species not detected by the Candida probe (b, C. famata; c, Cryptococcus neoformans; d, Aspergillus fumigatus) and (e) a negative control (water).

\section{Sensitivity of the nested Candida PCR assay}

In order to determine the lower sensitivity limit, blood from healthy individuals was spiked with $C$. albicans cells in the range $10^{3}$ to 0 c.f.u. $\mathrm{ml}^{-1}$ and DNA was extracted as described above. The first-round PCR gave an amplicon of around $200 \mathrm{bp}$, although this was not always visible, depending on the size of the initial spike. This extra amplification step improved the detection of Candida to 1 c.f.u. $\mathrm{ml}^{-1}$ (Fig. 4), a figure that is comparable with results published for NASBA and PCR-ELISA detection of Candida.

When comparing the single-round PCR assay with the nested PCR assay, the crossing-points were as follows: for 250 c.f.u. $\mathrm{ml}^{-1}, 26$ cycles for the single-round versus 7 cycles for the nested; for 30 c.f.u. $\mathrm{ml}^{-1}, 30$ cycles for the single-round versus 15 cycles for the nested; and, for 5 c.f.u. $\mathrm{ml}^{-1}, 32$ cycles for the single-round versus 19 cycles for the nested PCR (Fig.

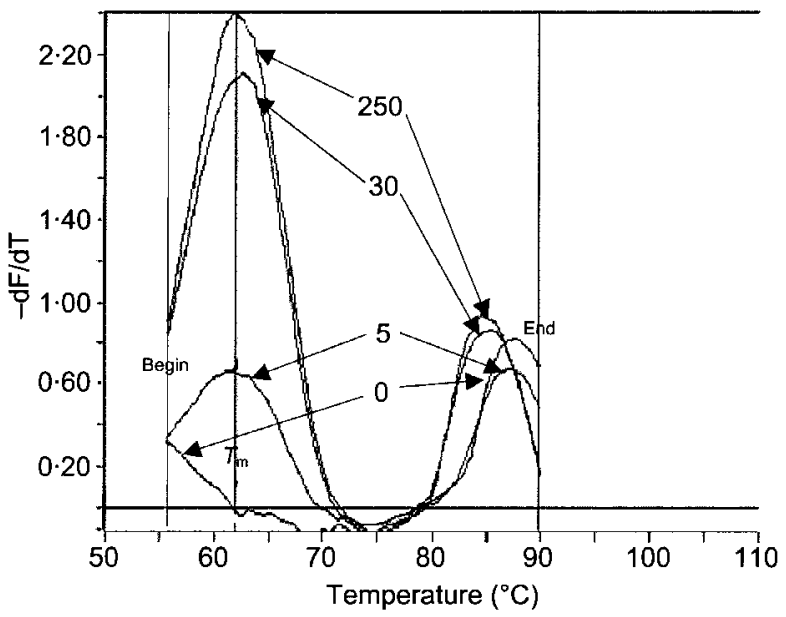

Fig. 3. Determination of the sensitivity of the single-round Candida PCR assay. Whole blood from healthy individuals was spiked with serial dilutions of $C$. albicans cells $\left(250,30,5\right.$ or 0 c.f.u. $\left.\mathrm{ml}^{-1}\right)$ and then extracted.

5). As the crossing-point is dependent on the initial template concentration, the results indicate that the nested PCR assay has greatly increased the template concentration and has therefore improved the sensitivity of the overall assay. The results for the single-round PCR assay are consistent with results published for experiments on both the Roche LightCycler system and block-based assays (Einsele et al., 1997; Loeffler et al., 2000b).

\section{Analysis of clinical samples}

In interpreting the results from the 472 EDTA-whole blood samples tested, a number of factors need to be considered. Due to the increased chances of contamination involved with a nested PCR, only samples that were positive by both the single-round Light-Cycler assay and the nested PCR assay could initially be regarded as PCR-positive; any samples that were only positive by the nested PCR method were repeated before they were considered PCR-positive. All of the PCRpositive samples tested were positive by both assays. To confirm the results, samples that were considered PCRpositive were also tested by RFLP. All of the samples that were positive by PCR were also positive by RFLP (results not shown). To rule out contamination during the first DNA extraction, any patient that was initially considered PCRpositive for Candida had a follow-up sample taken and only if this second sample gave a PCR-positive result was the patient considered to have possible candidiasis.

The PCR method detected candidal DNA in 27 of the 113 (23.9\%) patients tested (42 of 472 samples tested), but only $11(9.7 \%)$ of these patients had multiple samples that were PCR-positive, the other $16(14 \cdot 2 \%)$ had only a single PCRpositive sample. Concurrent with the PCR, all the patients were tested for fungal infection by blood culture. Of the 113 patients investigated, only $3(2.7 \%)$ had Candida-positive 


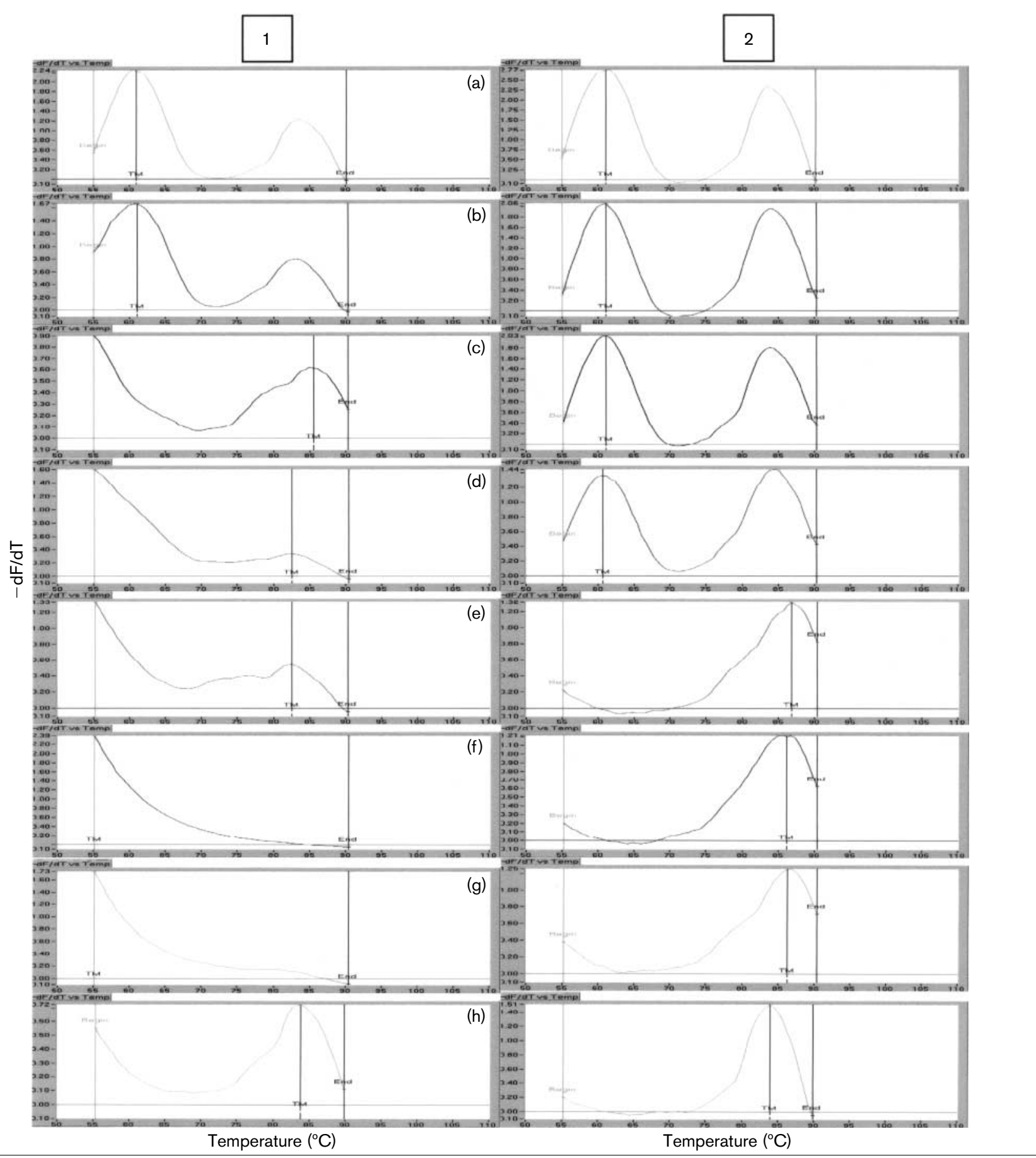

Fig. 4. Determination of the sensitivity of the single-round Candida PCR assay (column 1) and the nested Candida PCR assay (column 2) using serially diluted C. albicans cells extracted from spiked whole blood from healthy individuals. (a) C. albicans positive control. (b)-(g) Dilutions containing 5 (b), 2 (c), 1 (d), 0.5 (1 c.f.u. in 2 ml) (e), 0.25 (1 c.f.u. in 4 ml) (f) or 0 c.f.u. ml ${ }^{-1}$ (g). (h) Water control.

blood cultures, compared with $27(23.9 \%)$ positive by PCR. Two of the blood culture Candida-positive patients were also positive for Candida by PCR, although one of the blood culture Candida-positive patients was not detected by the Candida PCR; however, this patient had received 5 days of antifungal treatment before a sample was sent for fungal PCR analysis. The sample was positive for Aspergillus by RFLP (Table 1). None of the samples that were PCR-negative for both Candida and Aspergillus were positive by blood culture.

On the basis of Aspergillus RFLP analysis, a further 15 (13.3\%) patients were positive for Aspergillus DNA (results 


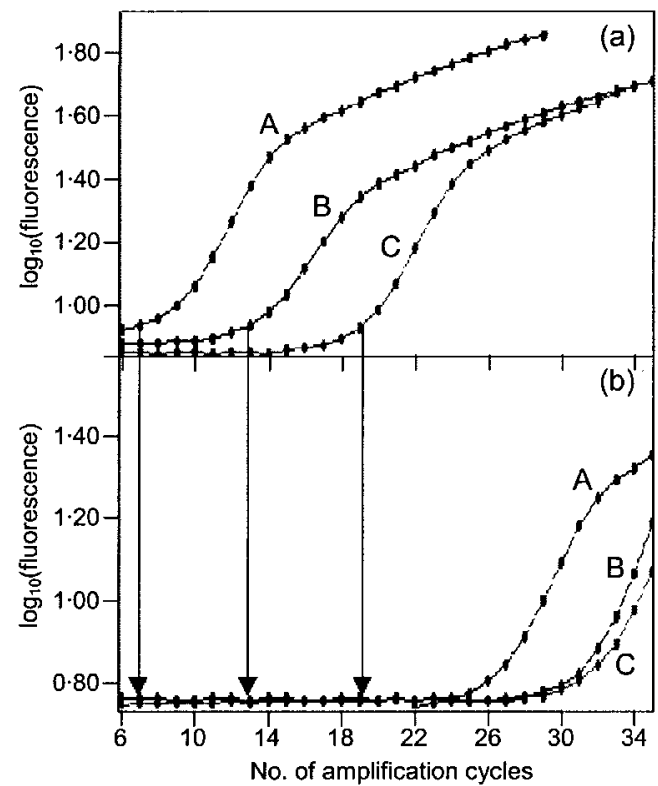

Fig. 5. Crossing-points of fluorescence of serially diluted $C$. albicans cells extracted from spiked whole blood from healthy individuals. Curves show dilutions containing 250 (curves A), 30 (B) or 5 (C) c.f.u. $\mathrm{ml}^{-1}$. (a) Serial dilutions already amplified by the first round of the nested PCR. (b) Serial dilutions amplified by the Light-Cycler system only.

not shown), but only $5(4.4 \%)$ of these had multiple PCR/ RFLP-positive results. Computed tomography (CT) scans and chest X-rays indicated that nine of these patients were suspected of having an opportunistic lung infection and one of these patients also had positive Aspergillus histopathology results, including $A$. niger colonization of lung, brain, heart and discs of the lumbar region. On extracting DNA from the heart and lung tissue, RFLP analysis confirmed the presence of Aspergillus. Sequencing of the Aspergillus PCR product identified the species as $A$. niger, thus confirming the histopathology results. None of the patients had Aspergilluspositive blood cultures.

Microbiological data revealed that the patients that were PCR-positive for Candida or Aspergillus tended to have higher levels of fungal colonization at superficial sites. Of the 27 patients who were Candida PCR-positive, 59.3\% had superficial fungal colonization [predominantly $(81.3 \%)$ Candida species; Table 1]. Eight of the 15 patients who were Aspergillus RFLP-positive were also colonized, mainly by Candida species (75\%). Only 16 of the $71(22.5 \%)$ patients who were consistently PCR-negative showed any signs of superficial colonization (Table 1).

In total, $37 \cdot 2 \%(14 \cdot 1 \%$ using multiple-sample PCR-positives only) of the suspected cases were positive for Candida (23.9/9.7\%) and Aspergillus (13.3/4.4\%) as determined by the PCR/RFLP method, whereas blood culture only detected Candida in 3 of $113(2.7 \%)$ cases, and no Aspergillus was cultured. One patient was Candida PCR-negative but positive for Candida by blood culture, although this patient had received antifungal treatment before being tested by PCR.

\section{DISCUSSION}

With the development of real-time PCR, progress has been made in the development of techniques for the detection of infectious organisms. Most of this research has been directed at detecting viruses (Schroter et al., 2001; Kawai et al., 1999; Funato et al., 2001; Whalley et al., 2001; van Elden et al., 2001; Schutten et al., 2000) and bacteria (Corless et al., 2001;

Table 1. Colonization of patients tested by PCR/RFLP

\begin{tabular}{|lccc|}
\hline Fungus cultured & $\begin{array}{c}\text { Candida PCR- } \\
\text { positive }(\boldsymbol{n}=\mathbf{2 7})\end{array}$ & $\begin{array}{c}\text { Aspergillus } \\
\text { RFLP-positive } \\
(\boldsymbol{n}=\mathbf{1 5})\end{array}$ & $\begin{array}{c}\text { PCR/RFLP- } \\
\text { negative }(\boldsymbol{n}=71)\end{array}$ \\
\hline C. albicans & 6 & $4^{*}$ & 6 \\
C. glabrata & 1 & 0 & 2 \\
C. parapsilosis & $1 \dagger$ & 0 & 2 \\
C. albicans and C. glabrata & 1 & 2 & 1 \\
C. glabrata and C. krusei & 1 & 0 & 1 \\
C. albicans and A. fumigatus & 1 & 0 & 1 \\
C. albicans, C. glabrata and A. fumigatus & 1 & 0 & 0 \\
Candida sp. & $3 \dagger$ & 0 & 1 \\
A. fumigatus & 0 & 1 & 0 \\
A. fumigatus and A. flavus & 1 & 0 & 2 \\
Others & 0 & 1 & 55 \\
None & 11 & 7 & 0 \\
\hline
\end{tabular}

${ }^{\star}$ One of these patients had superficial and deep-seated Candida (blood culture) infection. This patient was not positive for Candida by PCR.

$\dagger$ These patients had superficial and deep-seated Candida (blood culture) colonization. 
Rantakokko-Jalava \& Jalava, 2001; Qi et al., 2001; Mygind et al., 2001), with less work focused on the detection of fungi (Loeffler et al., 2000a, b; Palladino et al., 2001). With the number and range of opportunistic fungal infections increasing and the necessity for early diagnosis, the development of a real-time method for fungal detection is imperative (Chen et al., 2000; Reiss \& Morrison, 1993; Gleason et al., 1997).

Approximately $80 \%$ of systemic fungal infections are caused by Candida species, with $60 \%$ of these infections caused by $C$. albicans, although there are an increasing number of cases of infection caused by non-C. albicans species such as $C$. tropicalis, C. parapsilosis, C. glabrata and C. krusei. It was therefore crucial to design a system that would be able to detect all these species without the need for time-consuming post-amplification handling, e.g. RFLP analysis. By developing a fluorescently labelled probe for use on the Light-Cycler system, we were able to detect C. albicans, C. parapsilosis, $C$. tropicalis, C. krusei and C. glabrata as well as C. kefyr and C. dubliniensis, with no cross-hybridization with other major fungal pathogens (Fig. 2). In terms of epidemiology, it would have been beneficial to design species-specific probes that could have been used for samples that were positive with the pan-candidal probe, and this may be pursued in the future, although this would increase the work-load. It is also beneficial to distinguish between azole-sensitive and azoleresistant Candida strains and so provide information on the appropriate antifungal therapy; Loeffler et al. (2000a) have developed a Light-Cycler-based method for this.

It has been suggested that the fungal load in blood samples is frequently lower than 10 c.f.u. $\mathrm{ml}^{-1}$ of blood, with $25 \%$ of cases having a fungal load of 1 c.f.u. $\mathrm{ml}^{-1}$ or below. As such a very small amount of fungal DNA would be present (Loeffler et al., 2000b), the sensitivity of the assay is critical. By targeting the multicopy (> 100 copies; Einsele et al., 1997) $18 \mathrm{~S}$ rRNA gene, the sensitivity of the assay is enhanced. Without the nested PCR, the Light-Cycler/probe system was able to detect as little as to 5 c.f.u. $\mathrm{ml}^{-1}$ reproducibly, thus detecting most cases of candidal infection. To enhance the sensitivity further, a nested PCR was developed and this allowed reproducible detection down to 1 c.f.u. $\mathrm{ml}^{-1}$, a level comparable with other published techniques. To keep the assay within 1 working day, the single-round assay should be employed, but it should be noted that, if the first round of the nested PCR is performed overnight, the nested PCR assay can be completed in less than 1.5 working days.

The use of PCR-ELISA has been shown to be $100 \%$ specific at a sensitivity level of 5 c.f.u. $\mathrm{ml}^{-1}$ of blood (Loeffler et al., 1998), but this technique costs more per sample and takes considerably longer than a Light-Cycler reaction. The same is true for the use of Southern blotting; Einsele et al. (1997), using a variety of probes to detect Candida species, reported a sensitivity of 10 to $50 \mathrm{fg}$ DNA, which was equivalent to 1 c.f.u. $\mathrm{ml}^{-1}$ of blood. Although species-level identification was achieved, the sample handling time was considerable, depending on the fungal species causing the infection. The most promising alternative to the Light-Cycler system is the use of NASBA. Research has been carried out for the detection of both Candida and Aspergillus species (Widjojoatmodjo et al., 1999; Loeffler et al., 2001) and indicated a comparable sensitivity limit of 1 c.f.u. $\mathrm{ml}^{-1}$ blood, with few drawbacks. The rapid sample turn-around and high sensitivity of NASBA make it a good alternative for the detection of infection.

Contamination is accepted as a major problem in detecting fungal infection, especially in amplification techniques based on the use of pan-fungal primers. As yeasts and moulds are ubiquitous in the environment, controlling contamination of extraction and PCR reagents is essential. When using a nested PCR system, it is imperative that every precaution is taken to minimize the chance of cross-contamination and that all positive results need repeat confirmation. The presence of fungal DNA in the enzyme Zymolyase has been reported previously (Rimek et al., 1999; Loeffler et al., 1999) and, on testing three batches of the enzyme, we discovered DNA from S. cerevisiae (results not shown). On testing DNA extracted from S. cerevisiae on the Light-Cycler, there was amplification by PCR but no cross-reactivity with the Candida probe and, on comparing S. cerevisiae 18S rRNA sequence data, it was decided that no cross-reactivity was likely to occur.

Occasionally, batches of $10 \times$ PCR buffer have been found to contain fungal DNA (Loeffler et al., 1999), and this highlights the problems in detecting fungal infections confidently using commercial reagents. It has been predicted that only a finite number of airborne fungal species contaminate samples during the extraction procedure and that the rate of contamination is no greater than any other PCR technique (Loeffler et al., 1999). Nevertheless, with the development of new procedures with improved sensitivities, the problem may become more apparent. It is therefore essential that the specificities of assays be vigorously confirmed.

The actual source of fungal nucleotides in the blood of patients suffering from fungaemia is still unknown. Whether they are extracted from intact cells (including non-viable/ non-culturable cells) circulating in the bloodstream or from fungal cells that have been engulfed by white blood cells, or from free nucleic acid, remains unclear. This and other research confirms that it is possible to extract and detect DNA/RNA from intact fungal cells spiked into whole blood, although it is undecided whether this is the case in the clinical scenario. It has also been hypothesized that candidal cells or nucleic acids may pass into the bloodstream by absorption through the gut lining and give rise to one-off (false) positive results (as is the case with galactomannan/mannan and the ELISA assays). In this study, over 80 clinical DNA extractions were performed and, each time, a negative extraction control (EDTA blood from a healthy individual) was included. In total, 15 healthy volunteers donated blood on at least three separate occasions and not once did the negative control give a positive result. Although this evidence suggests that false positives due to adsorption of fungal cells/nucleic acid 
through the gut is unlikely, it cannot be excluded in the clinical scenario, where the cytotoxic effects of many antibiotics may damage the gut lining.

The use of 18S rRNA genes for the detection and identification of many fungi has been described extensively (Einsele et al., 1997; Jaeger et al., 2000; Mathis et al., 1997; Widjojoatmodjo et al., 1999; Loeffler et al., 2000b, 2001), as has the possibility of using the internal transcribed spacer (ITS) regions between the actual rRNA genes (Chen et al., 2000; Williams et al., 1995; White et al., 1990). Being less highly conserved than the rRNA genes, targeting the ITS regions would allow easier species-level identification and this could be applied to the Light-Cycler system. For example, within the genus Candida, the ITS2 region varies in size from $251 \mathrm{bp}$ for Candida lustianiae up to $428 \mathrm{bp}$ for $C$. kefyr (Chen et al., 2000), and this variation could be exploited. One of the benefits of the Light-Cycler system is its ability to differentiate PCR amplicons by analysis of their melting curves. The melting temperature of the amplicon is dependent on the $\mathrm{G}+\mathrm{C}$ content, length and sequence, and Ririe et al. (1997) predict that a $1 \mathrm{~kb}$ amplicon would melt at a temperature $12{ }^{\circ} \mathrm{C}$ higher than would a 40 bp primer dimer of similar $\mathrm{G}+\mathrm{C}$ content. The actual melting temperature of the PCR product is also a function of the rate of temperature transition, with a slower rate of temperature transition providing greater melting temperature precision (Ririe et al., 1997). By carefully designing a pan-Candida probe, we may be able to achieve species-level identification for a range of Candida species within a single Light-Cycler reaction and so provide a much higher standard of differentiation but within a much shorter time-scale.

In conclusion, the single-round Light-Cycler system developed provides a rapid, accurate and reproducible method that combines the enhanced sensitivity and increased specificity of probe hybridization for the detection of the most common forms of systemic candidal infection. The sensitivity of the assay can be improved by utilizing the nested LightCycler, but this will increase the time to detection and increase the complexity of the assay. As primers are panfungal, the assay can be easily modified for the detection of other pathogenic and/or opportunistic fungal infections by the design of specific probes.

The clinical relevance of the PCR results in most cases still remains uncertain. Only two of the PCR positives were confirmed by a positive blood culture, although the confirmation of a PCR result by a technique known to be much less sensitive does seem unwise. Of the 11 patients with multiple Candida PCR-positive results, seven were treated with liposomal amphotericin $\mathrm{B}$; all seven responded to treatment and all became Candida PCR negative. Of the four remaining patients, two were treated with fluconazole but did not respond, whilst the other two were not treated and the symptoms in one of these patients did resolve. However, under the current consensus criteria for the diagnosis of fungaemia (Ascioglu et al., 2002), a case with multiple PCR positives does not provide enough evidence to prove a case of invasive Candida or Aspergillus infection and, at most, it can be used as one criterion in defining a probable case of fungaemia. The PCR result must, at all times, be collated with other clinical evidence: radiology (CT scans and chest $\mathrm{X}$-rays), culture (both superficial and deep-seated colonization), histopathology (if available), patient history [underlying illness, current therapy (including antifungal treatment), previous fungal infections, other opportunistic infections (e.g. cytomegalovirus)] and other lab-based assays (ELISA or latex agglutination for the detection of mannan or galactomannan). Using the above information, only three cases in this study could be classified as proven candidaemias; the cases with multiple PCR-positive results were considered as probable fungaemias, while the cases with single PCR positives were considered as possible or suspected fungaemias.

At the present time, it is still not possible to prove a case of fungaemia without a positive blood culture combined with the compatible clinical symptoms, but it is hoped that further research into fungal PCR will provide a credible method to overcome the sensitivity limitations of blood culture.

\section{REFERENCES}

Altschul, S. F., Madden, T. L., Schaffer, A. A., Zhang, J., Zhang, Z., Miller, W. \& Lipman, D. J. (1997). Gapped BLAST and PSI-BLAST: a new generation of protein database search programs. Nucleic Acids Res 25, 3389-3402.

Ascioglu, S., Rex, J. H., de Pauw, B. \& 17 other authors (2002). Defining opportunistic invasive fungal infections in immunocompromised patients with cancer and hematopoietic stem cell transplants: an international consensus. Clin Infect Dis 34, 7-14.

Chen, Y. C., Eisner, J. D., Kattar, M. M., Rassoulian-Barrett, S. L., LaFe, K., Yarfitz, S. L., Limaye, A. P. \& Cookson, B. T. (2000). Identification of medically important yeasts using PCR-based detection of DNA sequence polymorphisms in the internal transcribed spacer 2 region of the rRNA genes. J Clin Microbiol 38, 2302-2310.

Corless, C. E., Guiver, M., Borrow, R., Edwards-Jones, V., Fox, A. J. \& Kaczmarski, E. B. (2001). Simultaneous detection of Neisseria meningitidis, Haemophilus influenzae, and Streptococcus pneumoniae in suspected cases of meningitis and septicemia using real-time PCR. J Clin Microbiol 39, 1553-1558.

Denning, D. W. (1998). Invasive aspergillosis. Clin Infect Dis 26, 781-803.

Einsele, H., Hebart, H., Roller, G. \& 8 other authors (1997). Detection and identification of fungal pathogens in blood by using molecular probes. J Clin Microbiol 35, 1353-1360.

Funato, T., Satou, N., Abukawa, D., Satou, J., Abe, Y., Ishii, K. K., linuma, K., Kaku, M. \& Sasaski, T. (2001). Quantitative evaluation of cytomegalovirus DNA in infantile hepatitis. J Viral Hepat 8, 217-222.

Gleason, T. G., May, A. K., Caparelli, D., Farr, B. M. \& Sawyer, R. G. (1997). Emerging evidence of selection of fluconazole-tolerant fungi in surgical intensive care units. Arch Surg 132, 1197-1201.

Guiver, M., Levi, K. \& Oppenheim, B. A. (2001). Rapid identification of Candida species by Taqman PCR. J Clin Pathol 54, 362-366.

Jaeger, E. E. M., Carroll, N. M., Choudhury, S., Dunlop, A. A., Towler, H. M., Matheson, M. M., Adamson, P., Okhravi, N. \& Lightman, S. (2000). Rapid detection and identification of Candida, Aspergillus, and Fusarium species in ocular samples using nested PCR. J Clin Microbiol 38, 2902-2908. 
Kawai, S., Yokosuka, O., Kanda, T., Imazeki, F., Maru, Y. \& Saisho, H. (1999). Quantification of hepatitis C virus by TaqMan PCR: comparison with HCV Amplicor Monitor assay. J Med Virol 58, 121-126.

Lehmann, P. F., Lin, D. \& Lasker, B. A. (1992). Genotypic identification and characterization of species and strains within the genus Candida by using random amplified polymorphic DNA. J Clin Microbiol 30, 3249-3254.

Loeffler, J., Hebart, H., Schumacher, U., Reitze, H. \& Einsele, H. (1997). Comparison of different methods for extraction of DNA of fungal pathogens from cultures and blood. J Clin Microbiol 35, 3311-3312.

Loeffler, J., Hebart, H., Sepe, S., Schumacher, U., Klingebiel, T. \& Einsele, H. (1998). Detection of PCR-amplified fungal DNA by using a PCR-ELISA system. Med Mycol 36, 275-279.

Loeffler, J., Hebart, H., Bialek, R., Hagmeyer, L., Schmidt, D., Serey, F. P., Hartmann, M., Eucker, J. \& Einsele, H. (1999). Contaminations occurring in fungal PCR assays. J Clin Microbiol 37, 1200-1202.

Loeffler, J., Hagmeyer, L., Hebart, H., Henke, N., Schumacher, U. \& Einsele, H. (2000a). Rapid detection of point mutations by fluorescence resonance energy transfer and probe melting curves in Candida species. Clin Chem 46, 631-635.

Loeffler, J., Henke, N., Hebart, H., Schmidt, D., Hagmeyer, L., Schumacher, U. \& Einsele, H. (2000b). Quantification of fungal DNA by using fluorescence resonance energy transfer and the Light Cycler system. J Clin Microbiol 38, 586-590.

Loeffler, J., Hebart, H., Cox, P., Flues, N., Schumacher, U. \& Einsele, H. (2001). Nucleic acid sequence-based amplification of Aspergillus RNA in blood samples. J Clin Microbiol 39, 1626-1629.

Mathis, A., Weber, R., Kuster, H. \& Speich, R. (1997). Simplified sample processing combined with a sensitive one-tube nested PCR assay for detection of Pneumocystis carinii in respiratory specimens. J Clin Microbiol 35, 1691-1695.

Metzgar, D., van Belkum, A., Field, D., Haubrich, R. \& Wills, C. (1998). Random amplification of polymorphic DNA and microsatellite genotyping of pre- and posttreatment isolates of Candida spp. from human immunodeficiency virus-infected patients on different fluconazole regimens. J Clin Microbiol 36, 2308-2313.

Morace, G., Sanguinetti, M., Posteraro, B., Lo Cascio, G. \& Fadda, G. (1997). Identification of various medically important Candida species in clinical specimens by PCR-restriction enzyme analysis. J Clin Microbiol 35, 667-672.

Mygind, T., Birkelund, S., Falk, E. \& Christiansen, G. (2001). Evaluation of real-time quantitative PCR for identification and quantification of Chlamydia pneumoniae by comparison with immunohistochemistry. J Microbiol Methods 46, 241-251.

Nishikawa, A., Sugita, T. \& Shinoda, T. (1999). Rapid identification of Debaryomyces hansenii/Candida famata by polymerase chain reaction. Med Mycol 37, 101-104.

Palladino, S., Kay, I., Fonte, R. \& Flexman, J. (2001). Use of real-time PCR and the LightCycler system for the rapid detection of Pneumocystis carinii in respiratory specimens. Diagn Microbiol Infect Dis 39, 233-236.
Qi, Y., Patra, G., Liang, X., Williams, L. E., Rose, S., Redkar, R. J. \& DelVecchio, V. G. (2001). Utilization of the $r p o B$ gene as a specific chromosomal marker for real-time PCR detection of Bacillus anthracis. Appl Environ Microbiol 67, 3720-3727.

Rantakokko-Jalava, K. \& Jalava, J. (2001). Development of conventional and real-time PCR assays for detection of Legionella DNA in respiratory specimens. J Clin Microbiol 39, 2904-2910.

Reiss, E. \& Morrison, C. J. (1993). Nonculture methods for diagnosis of disseminated candidiasis. Clin Microbiol Rev 6, 311-323.

Rimek, D., Garg, A. P., Haas, W. H. \& Kappe, R. (1999). Identification of contaminating fungal DNA sequences in Zymolyase. J Clin Microbiol 37, 830-831.

Ririe, K. M., Rasmussen, R. P. \& Wittwer, C. T. (1997). Product differentiation by analysis of DNA melting curves during the polymerase chain reaction. Anal Biochem 245, 154-160.

Schroter, M., Zollner, B., Schafer, P., Laufs, R. \& Feucht, H. H. (2001). Quantitative detection of hepatitis $\mathrm{C}$ virus RNA by light cycler PCR and comparison with two different PCR assays. J Clin Microbiol 39, 765-768.

Schutten, M., van den Hoogen, B., van der Ende, M. E., Gruters, R. A Osterhaus, A. D. \& Niesters, H. G. (2000). Development of a real-time quantitative RT-PCR for the detection of HIV-2 RNA in plasma. J Viro Methods 88, 81-87.

van Elden, L. J., Nijhuis, M., Schipper, P., Schuurman, R. \& van Loon, A. M. (2001). Simultaneous detection of influenza viruses A and B using real-time quantitative PCR. J Clin Microbiol 39, 196-200.

Whalley, S. A., Brown, D., Teo, C. G., Dusheiko, G. M. \& Saunders, N. A. (2001). Monitoring the emergence of hepatitis $B$ virus polymerase gene variants during lamivudine therapy using the LightCycler. J Clin Microbiol 39, 1456-1459.

Whimbey, E., Kiehn, T. E., Brannon, P., Blevins, A. \& Armstrong, D. (1987). Bacteremia and fungemia in patients with neoplastic disease. Am J Med 82, 723-730.

White, T. J., Burns, T., Lee, S. \& Taylor, J. (1990). Amplification and direct sequencing of fungal ribosomal RNA genes for phylogenetics. In PCR Protocols: a Guide to Methods and Applications, pp.315-322. Edited by M. A. Innis, D. H. Gelfand, J. J. Sninsky \& T. J. White. San Diego: Academic Press.

Widjojoatmodjo, M. N., Borst, A., Schukkink, R. A. F., Box, A. T., Tacken, N. M., Van Gemen, B., Verhoef, J., Top, B. \& Fluit, A. C. (1999). Nucleic acid sequence-based analysis (NASBA) detection of medically important Candida species. J Microbiol Methods 38, 81-90.

Williams, D. W., Wilson, M. J., Lewis, M. A. O. \& Potts, A. J. C. (1995) Identification of Candida species by PCR and restriction fragment length polymorphism analysis of intergenic spacer regions of ribosomal DNA. J Clin Microbiol 33, 2476-2479.

Wright, W. L. \& Wenzel, R. P. (1997). Nosocomial Candida. Epidemiology, transmission, and prevention. Infect Dis Clin North Am 11, 411-425. 